\title{
Micronutrient programming of development throughout gestation
}

\author{
Cheryl J. Ashworth ${ }^{1}$ and Christos Antipatis ${ }^{2}$ \\ ${ }^{1}$ Scottish Agricultural College, Craibstone Estate, Bucksburn, Aberdeen AB21 9SB, UK; and \\ ${ }^{2}$ Rowett Research Institute, Greenburn Road, Bucksburn, Aberdeen AB21 9SB, UK
}

\begin{abstract}
Vitamins and minerals serve essential roles in cellular metabolism, maintenance and growth throughout life. They are also central components of many enzymes and transcription factors. However, the need for optimum amounts of key micronutrients at critical stages during the periovulatory period and subsequent embryonic and fetal life has become the focus of sustained research activity only recently. In addition to folic acid, the minerals zinc, iron and copper and the antioxidant vitamins A and E are of particular importance during pregnancy. Both excesses and deficiencies of these micronutrients can have profound and sometimes persistent effects on many fetal tissues and organs in the absence of clinical signs of deficiency in the mother. The consequences of micronutrient imbalance on the developing conceptus may not be apparent at the time of the nutritional insult, but may be manifest later in development. However, supplementary micronutrients provided later in gestation or during postnatal life cannot completely reverse the detrimental effects of earlier micronutrient imbalance. Importantly, deficiency of a specific micronutrient, such as zinc, during pregnancy can result in a greater incidence of fetal malformation and resorptions than general undernutrition. Given the range of micronutrients that affect development, the number of developmental stages susceptible to inappropriate micronutrient status and the diverse biochemical systems and types of tissue affected, it is challenging to propose a unifying hypothesis that could explain the effects of micronutrient imbalance on programming throughout gestation. Micronutrient imbalance can affect pregnancy outcome through alterations in maternal and conceptus metabolism, as a consequence of their essential role in enzymes and transcription factors and through their involvement in signal transduction pathways that regulate development. Micronutrient-induced disturbances in the balance between the generation of free oxygen radicals and the production of antioxidants that scavenge free radicals may provide an additional mechanistic explanation. The detrimental effects of many micronutrient deficiencies, particularly zinc and copper, can be alleviated by supplementary antioxidants, whereas deficiencies of antioxidant vitamins $\mathrm{A}$ and $\mathrm{E}$ are likely to reduce defence against free radical damage.
\end{abstract}

\begin{abstract}
Although the effects of macronutrients on the outcome of pregnancy have been the topic of many studies, the consequences of alterations in micronutrient (vitamin and mineral) supply on pre- and postnatal development are poorly understood. The dietary requirement for micronutrients during development is small; however, adequate amounts are essential for both the immediate and long-term well-being of the embryo, fetus and neonate. Micronutrients are involved in all stages of cell growth and differentiation, including cell signalling and protein translation, and are key elements of many enzymes and cell structures. Minerals are
\end{abstract}

Email: c.ashworth@ab.sac.ac.uk

This article is based on a presentation given at the British Society of Animal Science symposium 'Early Regulation of Mammalian Development' held in Aberdeen in September 2000. important as central components of catalytic enzyme sites and as stabilizing factors in enzymes and transcription factors. In addition to their crucial roles in cellular metabolism, maintenance and growth, many vitamins also regulate the expression of key developmental genes involved in the commitment of cells to specific lineages and pattern formation, and of genes involved in growth, proliferation and in the functional attributes of specific organs. Micronutrients also affect development by modifying changes in hormones, growth factors and cell signalling pathways that affect both nutrient uptake by the conceptus and the environment in which prenatal development proceeds. Severe micronutrient deficiencies during pregnancy lead to high rates of spontaneous abortion, fetal malformation and late fetal death. However, more moderate reductions, which occur in clinical and agricultural situations, also compromise pregnancy 
outcome. Research prompted by concern over the consequences of increased environmental concentrations of certain metals on reproductive outcome has highlighted that modest increases in several essential minerals can have detrimental effects on embryo development (see Hanna et al., 1997). Culture of two-cell mouse embryos in media containing various concentrations $(0.05-200.0 \mu \mathrm{mol} \mathrm{I-1})$ of minerals, including copper, manganese and zinc, for $72 \mathrm{~h}$ resulted in a reduction both in the number of embryos that formed blastocysts and in embryo cell number. Hanna et al. (1997) proposed that high concentrations of metals in embryo culture media may compromise embryo development as a consequence of oxidative damage, occurring through either direct oxidative reactions or after activation of reactive oxygen species through secondary mechanisms.

The effect of altered micronutrient intake on maternal function and subsequent development is complicated further by the numerous interactions that occur between micronutrients. For example, copper deficiency results in the accumulation of iron in certain tissues (Keen et al., 1998), lead-induced pathological changes in fetal kidney development are more pronounced in conditions of iron deficiency (Singh et al., 1991), and zinc deficiency can alter vitamin A (retinol) metabolism (Christian and West, 1998).

Different organs grow, differentiate and acquire functional competence at different stages of pregnancy. Their development is more sensitive to perturbations in nutrient supply during these 'critical windows' of differentiation (Robinson et al., 2000). In some situations, inappropriate nutrient supply during critical stages of pregnancy irreversibly programmes subsequent development.

Primary micronutrient deficiency arises through inadequate dietary intake and, during prenatal life, from inadequate placental nutrient transfer. Genetic factors can also influence the severity of micronutrient deficiency. For example, the incidence of swayback, a recognized symptom of copper deficiency, is higher in lambs born to Blackface ewes than in lambs born to Welsh mountain ewes grazing the same low-copper pasture (Weiner et al., 1978). Although these breed differences are believed to be the result of multiple genes, single gene defects are also implicated in copper deficiency. Menkes syndrome, which is characterized by progressive degeneration of the infant brain and spinal cord and failure to thrive, is thought to be due, in part, to maternal defects in a copper-transporting ATPase gene (Mercer et al., 1993). Certain diseases and therapeutic or recreational drugs also alter micronutrient status through altered uptake or metabolism. Several drugs chelate micronutrients, thereby reducing circulating concentrations, whereas plasma concentrations of antioxidant vitamins are lower in smokers compared with non-smokers with similar dietary habits. Maternal alcohol consumption during pregnancy alters retinol metabolism, as shown by increased concentrations of retinol in the fetal lung and kidney after maternal ethanol ingestion (Grummer and Zachman, 1990). Micronutrient deficiencies occurring before mating or during pregnancy can perturb the development of the preovulatory oocyte (Whaley et al., 2000), embryo (Olson and Seidel, 2000), fetoplacental unit (Antipatis et al., 2000) or offspring (Fisher and MacPherson, 1991) in the absence of obvious clinical signs of deficiency in the mother.

The consequences of specific micronutrient deficiencies can be more extreme and longer lasting than those occurring after general undernutrition. For example, feeding rats ad libitum from mating with a zinc-deficient diet increased both the number of malformations per fetus and the number of resorptions per litter compared with animals that received a control diet (Masters et al., 1983).

Numerous micronutrients affect pregnancy outcome. The micronutrients that appear to have the greatest impact include the minerals zinc, copper and iron and the antioxidant vitamins $\mathrm{A}$ and E. Many micronutrients are stored within the maternal body, and plasma concentrations decline only when such stores are depleted. For example, plasma retinol decreases only when hepatic stores are depleted and, therefore, a short-term deficiency in vitamin A during pregnancy is unlikely to have a major impact. In contrast, evidence that zinc deficiency during only a short period of pregnancy is teratogenic indicates that there is limited mobilization of zinc stores during periods of decreased supply.

Both copper and iron may elicit changes in prenatal development through the generation of free radicals as they undergo valency changes, whereas exposure of embryos to zinc-deficient conditions stimulates the upregulation of antioxidant enzymes. This review explores the possibility that altered antioxidant status is a unifying mechanism through which several micronutrients affect pregnancy outcome. The effects of these micronutrients at key stages of periovulatory and pre- and postnatal development will be considered. As the medical impact of altered micronutrient status on prenatal growth and pregnancy outcome has been the topic of a recent review (McArdle and Ashworth, 1999), this article will focus on current published studies that describe data obtained from animal studies.

\section{Oocyte maturation}

Knowledge of the role of micronutrients in oocyte and early embryonic development is based on data obtained from alterations to the maternal diet in vivo or after injection of micronutrients, coupled with data describing the effects of altered micronutrient content of oocyte or embryo culture media. Oocyte maturation involves both the synthesis of cytoplasmic components (cytoplasmic maturation) and a rearrangement and reduction in the chromosomes (nuclear maturation). Meiosis begins early in fetal life but is arrested and remains at the diplotene stage until the oocyte either degenerates during atresia or resumes meiosis just before ovulation in the mature female. Essential to the successful maturation of oocytes is the breakdown of the germinal vesicle surrounding the cumulus-oocyte complex. Recent data obtained after culture of rat cumulus-oocyte 
Table 1. Micronutrients that are important during the pre- or postimplantation stages of embryonic development

\begin{tabular}{|c|c|c|}
\hline \multirow[b]{2}{*}{ Stage of development } & \multicolumn{2}{|c|}{ Micronutrient } \\
\hline & Minerals & Vitamins \\
\hline Preimplantation & $\mathrm{Fe}, \mathrm{Cu}, \mathrm{Zn}, \mathrm{Cd}, \mathrm{Ca}, \mathrm{Ni}, \mathrm{Pb}, \mathrm{Co}$ & $\begin{array}{l}\text { A, E, B12, choline, folic acid, } \\
\text { pantothenate, riboflavin, inositol }\end{array}$ \\
\hline Postimplantation & $\mathrm{Cu}, \mathrm{Cd}, \mathrm{Zn}, \mathrm{Se}, \mathrm{Ca}$ & $\begin{array}{l}\text { A, E, B12, folic acid, pantothenate, } \\
\text { riboflavin, inositol }\end{array}$ \\
\hline
\end{tabular}

Both excesses and deficiencies of micronutrients affect development.

complexes with a range of antioxidants indicate that cellpermeant antioxidants inhibit germinal vesicle breakdown, thereby reducing the incidence of spontaneous resumption of meiosis (Takami et al., 1999). However, not all antioxidants exhibited this effect, and ascorbic acid and vitamin E were notable exceptions. In pigs, a single injection of retinyl palmitate approximately 6 days before mating increased the percentage of oocytes that progressed to metaphase II in vitro and promoted follicular homogeneity (Whaley et al., 2000). These observations extend earlier work from this group (Whaley et al., 1997) showing that a similar retinol injection regimen before mating was associated with increased pig embryo survival and reduced within litter variability in embryo development on day 12 of pregnancy. Collectively, these data indicate that nutritional modifications that enhance embryo survival may do so by affecting oocyte maturation.

\section{Embryo development}

Accumulating evidence indicates that altered nutrient supply during early embryonic development can impart long-term consequences on the subsequent viability of the conceptus and resultant offspring. Studies in vivo and in vitro have highlighted that the micronutrient environment in which embryos develop can alter the number of embryonic cells, the rate of blastocyst development and the commitment of cells to specific lineages, and can disrupt the balance between cell proliferation and programmed cell death (apoptosis). A summary of the primary micronutrients that affect embryo development is presented (Table 1).

Early mammalian embryos are susceptible to damage from reactive oxygen species (Johnson and Nasr-Esfahani, 1994) as shown by the fact that development of bovine embryos to blastocysts in vitro decreases in the presence of free radicals in a dose-dependent manner (Fujitani et al., 1997). Culture conditions in vitro appear to increase embryonic production of oxygen free radicals (Goto et al., 1993). Protection of embryonic cells from free radical damage by supplementing culture media with vitamin E for 7 days immediately after fertilization increased the number of bovine zygotes that developed to expanded blastocysts in vitro (Olson and Seidel, 2000). Furthermore, embryos cultured in the presence of vitamin E for 5.5 days between fertilization and transfer developed into larger blastocysts than did embryos cultured in control media, when assessed on day 12 . In other studies, vitamin E partially protected early murine embryos from the effects of heat shock (Arechiga et al., 1994), a cytotoxic effect thought to be mediated by free radicals. Similarly, survival and development of rat conceptuses explanted on day 8 of gestation was improved by culture with vitamin E (Steele et al., 1974).

The best known example of the importance of adequate maternal micronutrient intake is the requirement for adequate periconceptual intake of folic acid to reduce the incidence of neural tube defects. However, studies of folaterelated enzymes have failed to identify the metabolic defect in the neurulation stage embryo that is corrected by folic acid. Folic acid, together with vitamin B12, is an important methyl donor in many reactions, including the production of thymidine for DNA synthesis, polyamine synthesis and the biosynthesis of methionine from homocysteine. Given that homocysteine increases in folate depletion, high concentrations of this amino acid have been implicated as a possible factor associated with neural tube defects. In support of this hypothesis, treatment of avian embryos with homocysteine caused dysmorphogenesis of the heart and neural tube (Rosenquist et al., 1996); these defects were prevented by folate supplementation.

If sufficient cobalt is available, ruminant species do not require an external source of vitamin B12 for peptide synthesis. Cobalt deficiency during early ovine pregnancy is known to reduce lamb vigour at birth (Fisher and MacPherson, 1991); however, the cobalt-sensitive stages during embryo development have yet to be identified. Studies of the direct effects of cobalt on embryogenesis are confined to those on mouse embryos in vitro. The addition of $100 \mu \mathrm{mol}$ cobalt $\mathrm{I}^{-1}$ to the culture media reduced trophoblast proliferation in expanded murine blastocysts (Paksy et al., 1999). In addition to cobalt, small excesses of several metals in embryo culture media affect embryo development detrimentally (see Hanna et al., 1997). The tolerance of mouse embryos to excess nickel ions appears to increase as development progresses. Storeng and Jonsen (1980) reported that $10 \mu \mathrm{mol}$ nickel $\mathrm{I}^{-1}$ had an adverse effect on the morphology of two-cell embryos, whereas concentrations of $250-300 \mu \mathrm{mol} \mathrm{I} \mathrm{I}^{-1}$ were required to compromise 
the development of eight-cell embryos and blastocysts (Storeng and Jonsen, 1980; Paksy et al., 1999). Small excesses of cadmium, nickel and cobalt reduced trophoblast area in mouse trophoblasts (Paksy et al., 1999), although the minimum effective concentrations varied depending on the metal. The morphological alterations and loss of cellular contacts observed in the blastocysts would be expected to influence adhesion and recognition events adversely. Current hypotheses indicate that metal exposure is associated with increased intracellular reactive oxygen species and associated oxidative damage that affects embryo development adversely. However, at similar molar concentrations, redox active metals were found to be less embryotoxic than non-redox active metals (Hanna et al., 1997).

Embryos recovered from mice fed a zinc-deficient diet for a 3 or 6 day period encompassing oocyte maturation and fertilization had fewer cells and delayed blastocyst development in vitro (Peters et al., 1991). In preimplantation mouse embryos recovered from dams fed a zincdeficient diet for 3 days from the day before mating, zinc supplementation of the culture media did not improve blastocyst development (Peters et al., 1991). These data indicate that the effects of periconceptual zinc deficiency cannot be overcome by subsequent zinc supplementation. The mechanism by which zinc deficiency impairs embryo development is unclear. Zinc deficiency does not appear to affect the function of oocyte and embryonic membranes (Peters et al., 1993) or embryonic cell cycle characteristics (Rogers et al., 1995); however, recent data indicate that zinc deficiency induces apoptosis of embryonic cells in rats (Jankowski-Hennig et al., 2000). One possible mechanism underlying zinc deficiency-induced tissue alterations is excessive cellular oxidative damage after changes in free radical defence mechanisms. In a study using $3 T 3$ cells, Oteiza et al. (2000) demonstrated that exposure to zincdeficient conditions triggers intracellular responses associated with oxidative stress.

Evidence for the importance of copper for prenatal development arose from studies of enzootic ataxia (swayback) in lambs. This disease, which also occurs in pigs, goats and guinea-pigs, is characterized by spastic paralysis, severe lack of co-ordination and anaemia. In a series of studies Bennets et al. (1948) showed that the frequency and severity of the disease could be reduced markedly when cows were given supplementary copper either before or during early pregnancy. More recent studies involving culture in vitro of preimplantation murine embryos collected from dams that received a copperdeficient diet for 2 months before mating, showed that maternal copper deficiency reduced the number of blastocysts able to hatch from the zona pellucida (Menino et al., 1986). Rat embryos recovered from dams fed a copper-deficient diet for 4 weeks before mating were characterized at day 11 by an oedematous hindbrain (Jankowski et al., 1995). These effects were exacerbated by culture in copper-deficient media (Hawk et al., 1998). Rat embryos cultured in copper-deficient medium have impaired hindbrain and cardiac development, coupled with reduced antioxidant enzyme activity compared with those cultured in complete media (Hawk et al., 1998). In contrast to zinc deficiency, copper deficiency does not appear to promote apoptosis. Supplementation of copper-deficient media with antioxidants reduced the teratogenic effect, again implicating antioxidant status as a key factor in mediating the effects of micronutrients on embryo development.

It is well known that small amounts of copper from intrauterine contraceptive devices can prevent embryogenesis by blocking implantation and blastocyst development. Small excesses (50-100 $\mathrm{mol} \mathrm{I}^{-1}$ ) of copper in media used to culture mouse preimplantation embryos are also embryotoxic (Hanna et al., 1997), although the underlying mechanisms for the toxicity are unclear.

Retinoic acid, the most biologically active form of retinol, is an important regulator of cell division and differentiation in embryonic tissues. The effects of vitamin A deficiency and excess on embryo development are remarkably similar, indicating that embryonic cells must carefully regulate endogenous retinoic acid concentrations. In the nucleus, retinoic acid acts as a ligand to activate two families of transcription factors, the RA receptors (RAR) and the retinoid $X$ receptors $(R X R)$, which heterodimerize and bind to upstream responsive sequences of RA-responsive genes. To date, gene knockout studies have failed to identify the distinct roles of each RAR and RXR receptor subtype in embryogenesis, although fetuses carried by $R X R \alpha$ null mutant mice have occular and cardiac malformations and die from cardiac failure during mid-gestation, indicating that this receptor plays a vital role in heart development (Kastner et al., 1994).

Retinoic acid is believed to confer positional orientation during development. It is involved in the directional differentiation of the nervous system and is released by the 'zone of polarizing activity', which assigns positional value to limb bud cells. Studies using retinoid-synthesizing enzymes and their knockouts have revealed precise spacial distribution patterns of these enzymes in the early mouse embryo (reviewed by Maden, 2000). The expression of retinol dehydrogenases begins at the primitive streak stage, in which it is predominant in posterior tissues and the mesoderm. Retinoic acid also appears to be required for the left-right asymmetry of visceral organs during development. Addition of a retinoic acid receptor agonist to cultured headfold stage mouse embryos inhibits expression of genes that are normally expressed on the left side of the embryo. This treatment also leads to defects in cardiac anteroposterior patterning (Chazaud et al., 1999).

In domestic animals, retinol supplementation before mating has beneficial effects on embryo development. In superovulated ewes, injection of all-trans retinol increased the number of embryos that formed blastocysts in vitro (Eberhardt et al., 1999), whereas retinol injection of gilts before mating increased embryo survival and reduced intra- 
Table 2. Micronutrients that play a role in the development or function of fetal and neonatal organs

\begin{tabular}{lll}
\hline & \multicolumn{1}{c}{ Micronutrient } \\
\cline { 2 - 3 } Organ & \multicolumn{1}{c}{ Minerals } & \multicolumn{1}{c}{ Vitamins } \\
\hline \multirow{2}{*}{ Liver } & $\mathrm{Fe}, \mathrm{Se}, \mathrm{Cu}, \mathrm{Zn}, \mathrm{Cd}$ & $\mathrm{A}, \mathrm{B} 12$, choline, folic acid \\
Heart & $\mathrm{Cu}, \mathrm{Zn}$ & $\mathrm{A}, \mathrm{D}$ \\
Kidney & $\mathrm{Fe}, \mathrm{Cd}, \mathrm{Zn}, \mathrm{Pb}$ & $\mathrm{A}$ \\
Brain & $\mathrm{Fe}, \mathrm{Cu}, \mathrm{Zn}, \mathrm{I}$ & $\mathrm{A}, \mathrm{B} 6, \mathrm{~B} 12$, folic acid, biotin \\
Lung & $\mathrm{Cu}, \mathrm{Zn}, \mathrm{Cd}$ & $\mathrm{A}$ \\
Bone & $\mathrm{Ca}, \mathrm{Mg}$ & $\mathrm{D}, \mathrm{E}, \mathrm{C}$ \\
\hline
\end{tabular}

Both excesses and deficiencies of micronutrients affect development.

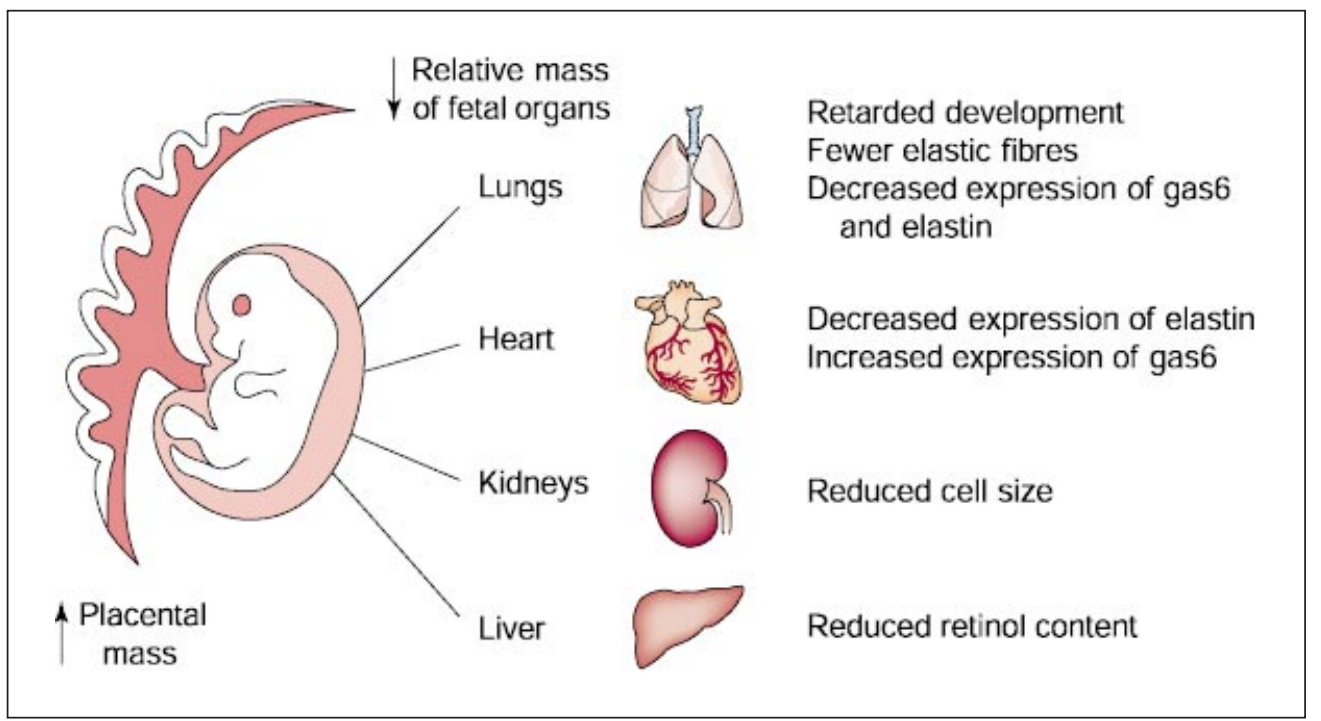

Fig. 1. Schematic representation of the effects of a $50 \%$ reduction in maternal plasma retinol concentrations on late fetal development in rats.

litter variability in blastocyst development on day 12 (Whaley et al., 1997). However, these studies did not distinguish whether the primary effect was an enhancement of oocyte quality or an increase in embryo development per se.

Culture of hamster blastocysts in medium containing 11 water-soluble vitamins and growth factors or in medium lacking one of these micronutrients indicated that the omission of only pantothenate, choline or inositol reduced the number of blastocysts that hatched (Kane and Bavister, 1988). More recently, McKiernan and Bavister (2000) demonstrated that the addition of pantothenate to culture media increased the size of hamster blastocysts. The percentage of live fetuses recovered after transfer of embryos cultured in supplementary pantothenate was greater than that after culture in control media.

\section{Effects on fetal development}

In addition to gross effects on fetal growth and survival, micronutrient deficiencies during fetal life are known to affect relative organ growth and can have profound and sometimes persistent effects on the molecular, cellular, immunological and morphological development of a range of fetal and neonatal tissues (summarized in Table 2).

Experimental reductions in maternal vitamin A deficiency during pregnancy are often achieved after consumption of a diet inadequate in vitamin $\mathrm{A}$ for several weeks before mating. In rats, consumption of a vitamin Afree diet for 7 weeks before mating and throughout pregnancy results in a $50 \%$ reduction in maternal plasma vitamin A concentrations during late pregnancy (Antipatis et al., 2000). In both rats (Antipatis et al., 2000) and pigs (Ashworth and Antipatis, 2001), such moderate maternal vitamin A deficiency is associated with asymmetrical fetal organ growth and reductions in the relative masses of fetal lungs, heart and liver during late pregnancy. In addition, studies in rats have shown that functional characteristics of the developing lung, kidney, heart and nervous system are also affected by maternal vitamin A status (Antipatis et al., 2000; Fig. 1). The developing lung is particularly sensitive 


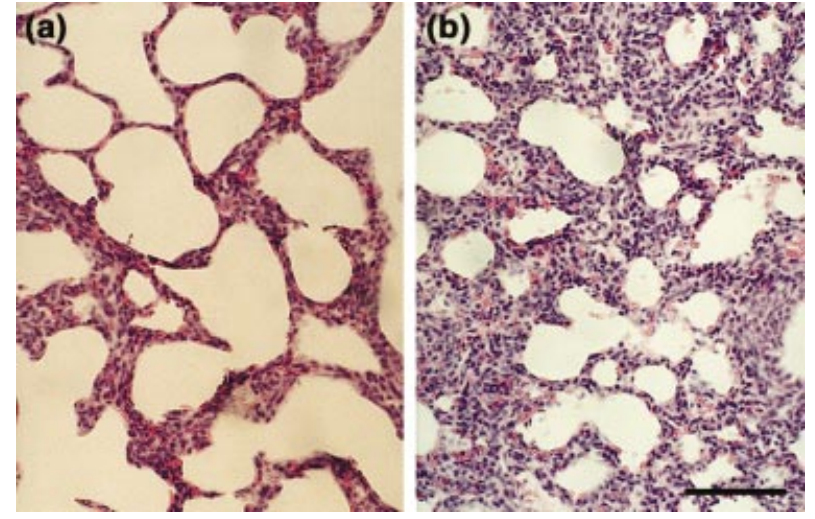

Fig. 2. Histological analysis of neonatal lung development in rats. (a) Typical lung morphology in a neonate carried by a control-fed animal. Saccular development is well advanced. (b) Typical lung morphology in a neonate carried by a vitamin A-deficient mother. Sacculi are more infrequent and less advanced compared with those in the neonate carried by the control animal. Scale bars represent $50 \mu \mathrm{m}$.

to changes in maternal vitamin A supply. The lungs of fetuses and neonates carried by vitamin A-deficient mothers are relatively lighter and morphologically immature, showing less branching of the bronchial passageways and reduced staining for elastic fibres compared with those from fetuses and neonates carried by control-fed dams (Fig. 2; Antipatis et al., 1998). In a subsequent experiment, dietary repletion with vitamin A from day 7 of pregnancy was used to restore maternal plasma retinol concentrations fully in rats fed a vitamin A-free diet for the preceding 9 weeks. Dietary repletion restored relative fetal and neonatal lung masses to values typical of fetuses and neonates carried by control-fed dams (Antipatis and Ashworth, 1999), indicating that some effects of maternal vitamin A deficiency are reversible. Furthermore, expression of the key structural and developmental genes, elastin and growth arrest specific gene 6 (Gas6) in lungs from vitamin A-deficient fetuses is decreased and these effects persist into perinatal life. Elastin synthesis is essential for the maturation of the alveoli, and the number and size of alveoli in turn determine the total lung capacity of the neonate. Other studies have shown that rat neonates born to vitamin A-deficient dams have reduced lung surfactant phospholipids accompanied by reduced expression of the gene for fatty acid synthetase, a key enzyme in the synthetic pathway for surfactant phospholipid precursors (Chailley-Heu et al., 1999). Moderate maternal vitamin A deficiency also affects the maturation of the fetal and neonatal kidney. Maternal retinol concentrations are correlated with the number of nephrons in the fetal rat kidney at day 21 (Lelievre-Pegorier et al., 1998) and modulate nephron endowment at birth. Although relative fetal and neonatal brain masses are unaffected by maternal vitamin A deficiency in rats (Antipatis et al., 2000), deficiency can lead to shortening of the caudal hindbrain and to perturbations associated with abnormal patterning of the posterior hindbrain and expansion of the anterior portion of the hindbrain in this species (White et al., 2000).

The beneficial effects of folate are not confined to events in early pregnancy. Marginal concentrations of maternal folate throughout gestation impair cellular growth and replication; women with low folate concentrations at week 28 of gestation have an approximately twofold greater risk of preterm delivery and low infant birth weight (Scholl et al., 1996). In pigs, folic acid injection at weaning, mating and during the first 12 weeks of gestation improves the number of live piglets at birth (Matte et al., 1984). The potential for folic acid supplementation to be more effective in pregnancies carrying greater numbers of embryos is consistent with the contention that folic acid may act by supporting DNA synthesis at critical stages of embryo development (Lindemann, 1993). In addition, folic acid treatment is associated with increased fetal protein content (Trembley et al., 1989; Harper et al., 1996).

Zinc deficiency is teratogenic in all species in which it has been examined. However, the severity of the perturbation of embryo development is not necessarily directly related to the degree of dietary deficiency. In an elegant experiment performed by Masters et al. (1983), fetal development was compared in rats offered zinc-sufficient or zinc-deficient diets ad libitum, or reduced quantities of the zinc-deficient diet. Consumption of the restricted amounts of the deficient diet led to tissue catabolism of zinc and resulted in fewer malformations and resorptions than seen in litters from dams fed the zinc-deficient diet ad libitum. Feeding rats a zinc-deficient diet from day 1 or day 3 of pregnancy led either to developmental retardation or to extensive apoptosis in the visceral arches, neural tube and somites by day 11 (Rogers et al., 1995). Removal of dietary zinc for as little as 4 days during week 2 of pregnancy increased apoptosis in neural crest cells. One of the possible mechanisms proposed to explain the effects of zinc deficiency on brain development is an impairment in the formation of the cytoskeletal network.

An inadequate fetal supply of selenium and vitamin $E$ during pregnancy is a contributory cause of fetal nutritive muscular dystrophy in calves, lambs and foals. Inadequate placental transport or metabolism of these nutrients has been implicated in addition to inadequate maternal intake (Bostedt and Schramel, 1990). However, more recent studies investigating selenium deficiency over six generations of rats indicate that there are regulatory mechanisms to conserve selenium in critical tissues (Bates et al., 2000). Evidence for such mechanisms was provided by observations that most tissues maintained concentrations of the selenium-rich iodothyronine deiodinase enzymes, and hence thyroid hormone production.

\section{Effects on placental development and function}

Micronutrient deficiencies can also alter placental development and the expression of key signalling molecules that are 
involved in establishing the balance between growth promotion and regulation at the fetal-placental interface. For example, vitamin A deficiency in rats increases the ratio of placental: fetal mass during late pregnancy (Antipatis et al., 2000); rats deficient in iron or vitamin A show increased placental expression of tumour necrosis factor $\alpha$ (TNF- $\alpha$ ) and leptin (Lea et al., 2000).

Mouse fetuses with a targeted disruption of the RXR $\alpha$ gene develop placental defects localized predominantly in the labyrinthine zone of the chorioallantoic placenta (Sapin et al., 1997). Reduction in maternal retinol status as a consequence of controlled periods of dietary withdrawal also alters placental function. Placentae from vitamin Adeficient rats show a marked infiltrate of neutrophils that are immunopositive for TNF- $\alpha$ and leptin. The number of apoptotic trophoblast cells increases in the tissue surrounding the neutrophils. Maternal vitamin A deficiency also alters the balance in apoptotic regulatory genes in the placenta. Trophoblast giant cell bax (pro-apoptosis) immunoreactivity was reduced as a consequence of vitamin A deficiency, whereas bcl-2 (anti-apoptosis) remained unchanged (Antipatis et al., 1997). These data indicate that the aberrant effects of maternal vitamin A deficiency on the fetal-placental unit may be associated with abnormal placental apoptosis induced by high concentrations of TNF$\alpha$ produced by infiltrating neutrophils or a change in the ratio of bcl-2: bax in the trophoblast giant cells.

Maternal iron deficiency does not appear to elicit morphological changes in the rat placenta; however, TNF- $\alpha$ and leptin were increased significantly in the spongiotrophoblast/giant cell region of the placenta (Lea et al., 2000). These results indicate that different mechanisms underlie the effects of micronutrients on cytokine production at the maternal-fetal interface.

\section{Effects on neonatal development}

Micronutrient deficiencies during pregnancy are often reflected in retarded neonatal organ maturation or in reduced neonatal vigour or cognitive development. Nutrition in utero can influence the ontogeny of the immune system and an individual's subsequent immunocompetence. For example, marginal zinc deficiency during pregnancy in rhesus monkeys was associated with reduced infant immune responsiveness, as measured by numbers of peripheral lymphocytes (Keen et al., 1989). This association occurred in the absence of marked reductions in infant plasma of soft tissue zinc concentrations. In ewes, subclinical cobalt deficiency during early pregnancy extends the time taken for lambs to stand, find the udder and suck (Fisher and MacPherson, 1991). The deficiency is also associated with a depression in passive immunity, reflected in lower lamb IgG concentrations. In pigs (Antipatis et al., 2001; Bland et al., 2001), maternal concentrations of fat-soluble vitamins during pregnancy are also related to neonatal IgG concentrations. Further work is required to clarify whether these associations reflect increased $\lg \mathrm{G}$ in colostrum or increased absorption of immunoglobulins across the neonatal gut. Supplementing ewes with vitamin E at 40 days before parturition increased lamb weight at day 45 of life, but this effect was not apparent by day 90 of life (Schultz et al., 1999). However, maternal vitamin E supplementation does not appear to affect the immune status of lambs, as measured by colostral or lamb serum IgG concentrations (Hatfield, et al., 1999; Schultz et al., 1999).

Maternal micronutrient status also affects brain function in offspring. For example, vitamin B6 deficiency during pregnancy in rats alters the function of N-methyl-Daspartate receptors, which are thought to play an important role in learning and memory (Guilarte, 1993). Furthermore, feeding rats zinc-deficient diets throughout pregnancy and lactation compromises microtubule formation in pup brains (Oteiza et al., 1990) and marginal maternal iron deficiency can impair postnatal motor development (Kwik-Uribe et al., 1999). Studies in rats have shown that iron deficiency anaemia during brain development leads to behavioural deficits that cannot be alleviated by iron treatment after weaning (Felt and Lozoff, 1996). As mentioned earlier, inadequate copper supply during early pregnancy is associated with a failure of co-ordination in lambs and other species. The biochemical factors associated with such altered brain development are unclear at present, but may involve excessive cellular oxidative damage or a reduction in brain concentrations of cuproenzymes (reviewed by Keen et al., 1998). Offspring of rat dams fed a copperdeficient diet during pregnancy and lactation have delayed maturation of the hippocampus (Hunt and Idso, 1995), the area of the brain responsible for learning and declarative memory. However, this study did not distinguish the relative contribution of inadequate maternal copper during the pre- and postnatal period.

In humans, severe maternal iodine deficiency can result in brain damage and mental retardation of offspring (reviewed by Delange, 2000). This damage is a consequence of the requirement of iodine for the synthesis of thyroid hormones, which in turn regulate the metabolic pattern of most organs, especially the brain. In rats, thyroid hormones are found in embryonic and fetal tissues before the onset of fetal thyroid function, and receptors for triiodothyronine (T3) are present in the brain by day 14 of gestation. Recent data demonstrate that iodine and selenium interact to alter thyroid function and that endemic cretinism may result from combined selenium and iodine deficiency, rather than iodine deficiency alone (for a review, see Arthur et al., 1999). In ewes, maternal iodine deficiency during late pregnancy induced low plasma thyroxine (T4) concentrations in newborn lambs, which was associated with increased susceptibility to hypothermia and decreased viability at birth (Caple and Nugent, 1982).

As mentioned previously, maternal retinoid status affects the development of the neonatal lung. Neonates from vitamin A-deficient rats (Antipatis et al., 2000) and pigs (Antipatis et al., 2001) have relatively smaller lungs than neonates from mothers fed normally. Respiratory failure is a 
common cause of perinatal mortality in rat pups born to vitamin A-deficient mothers (Antipatis et al., 1998). In pups that do survive, the lungs have less air space, smaller sacculi and fewer elastic fibres than do the lungs of contemporary pups from control-fed dams. Maternal copper deficiency during pregnancy is also associated with lung abnormalities. Lungs from neonatal rabbits born to dams fed copper-deficient diets have high proportions of poorly crosslinked elastin and collagen and low concentrations of surfactant phospholipids (Abdel et al., 1994). In rats, lungs from neonates carried by copper-deficient mothers show thickening of the air-blood barrier (Sarricolea et al., 1993), which reduces the efficiency of gaseous exchange.

\section{Conclusion}

Both micronutrient deficiencies and excesses have profound and sometimes persistent effects on the developmental competence of oocytes, conceptuses and neonates in all species studied to date. The consequences of a single micronutrient deficiency can be more severe than the effects of more general undernutrition, which can be overcome, at least partially, by maternal homeostatic mechanisms. Greater understanding of the role of key micronutrients and the impact of antioxidant status at key stages of development will provide new opportunities to refine nutritional guidelines designed to enhance pregnancy outcome.

SAC and RRI receive financial support from SEERAD.

\section{References}

Abdel Mageed AB, Welti R, Oehme FW and Pickrell JA (1994) Perinatal hypocuprosis affects synthesis and composition of neonatal lung collagen, elastin and surfactant American Journal of Physiology 267 L679-685

Antipatis C and Ashworth CJ (1999) Dietary supplementation during pregnancy counteracts the adverse effects of maternal vitamin A deficiency on fetal and neonatal lung growth and morphology in the rat Early Human Development 55 184-185

Antipatis C, McArdle HJ, Ashworth CJ, Brown D, Riley SC and Lea RG (1997) Effects of maternal vitamin A deficiency on placental morphology and function Journal of Reproduction and Fertility Abstract Series 201

Antipatis C, Ashworth CJ, Grant G, Lea RG, Hay SM and Rees WD (1998) Effects of maternal vitamin A status on fetal heart and lung: changes in expression of key developmental genes American Journal of Physiology 275 L1184-L1191

Antipatis C, Grant G and Ashworth CJ (2000) Moderate maternal vitamin A deficiency affects perinatal organ growth and development in rats British Journal of Nutrition 84 125-132

Antipatis C, Rooke JA, Ewen M and Ashworth CJ (2001) Both moderate vitamin A deficiency during pregnancy and birthweight affect piglet immunity Proceedings of the Nutrition Society $\mathbf{6 0}$ 72A

Arechiga CG, Ealy AD and Hansen PJ (1994) Efficacy of vitamin E and glutathione for thermoprotection of murine morulae Theriogenology 41 1545-1553

Arthur JR, Beckett GJ and Mitchell JH (1999) Interactions between iodine and selenium deficiencies in man and animals Nutrition Research Reviews 12 57-75

Ashworth CJ and Antipatis C (2001) Moderate vitamin A deficiency during pregnancy affects fetal organ growth in the pig Proceedings of the Nutrition Society 60 53A
Bates JM, Spate VL, Morris JS, St Germain DL and Galton VA (2000) Effects of selenium deficiency on tissue selenium content, deiodinase activity and thyroid hormone economy in the rat during development Endocrinology 141 2490-2500

Bennets HW, Beck AB and Hurley R (1948) The pathogenesis of falling disease: studies of copper deficiency in cattle Australian Veterinary Journal 24 237-244

Bland I, Sinclair AG, Bland VC and Edwards SA (2001) Effects of supplementing the maternal diet with vitamins and vaccinating the sow on immunoglobulin G concentrations in piglet plasma Proceedings of the Nutrition Society $6072 \mathrm{~A}$

Bostedt H and Schramel P (1990) The importance of selenium in the prenatal and postnatal development of calves and lambs Biology of Trace Element Research 24 163-171

Caple IW and Nugent GF (1982) Relationship between plasma thyroxine concentrations and the responses of newborn lambs to hypothermia Proceedings of the Australian Society of Animal Production 94657

Chailley-Heu B, Chelly N, Lelievre-Pegorier M, Barlier-Mur AM, MerletBenichou C and Bourbon JR (1999) Mild vitamin A deficiency delays fetal lung maturation in the rat American Journal of Respiratory Cell Molecular Biology 21 89-96

Chazaud C, Chambon P and Dolle P (1999) Retinoic acid is required in the mouse embryo for left-right asymmetry determination and heart morphogenesis Development 126 2589-2596

Christian P and West KP (1998) Interactions between zinc and vitamin A: an update American Journal of Clinical Nutrition 68 435S-441S

Delange $\mathbf{F}$ (2000) The role of iodine in brain development Proceedings of the Nutrition Society 59 75-79

Eberhardt DM, Will WA and Godkin JD (1999) Retinol administration to superovulated ewes improves in vitro embryonic viability Biology of Reproduction 60 1483-1487

Felt BT and Lozoff B (1996) Brain iron and behaviour of rats are not normalized by treatment of iron deficiency anemia during early development Journal of Nutrition 126 693-701

Fisher GEJ and MacPherson A (1991) Effect of cobalt deficiency in the pregnant ewe on reproductive performance and lamb viability Research in Veterinary Science 50 319-327

Fujitani Y, Kasai K, Ohtni S, Nishimura K, Yamada M and Utsumi K (1997) Effect of oxygen concentration and free radicals on in vitro development of in vitro produced bovine embryos Journal of Animal Science $\mathbf{7 5}$ 483-489

Goto Y, Noda Y, Mori T and Nakano M (1993) Increased generation of reactive oxygen species in embryos cultured in vitro. Theriogenology $\mathbf{1 5}$ $69-75$

Grummer MA and Zachman RD (1990) The effect of maternal ethanol ingestion on fetal vitamin A in the rat Pediatric Research 28 186-189

Guilarte TR (1993) Vitamin B6 and cognitive development: recent research findings from human and animal studies Nutrition Reviews 51 193-198

Hanna LA, Peters JM, Wiley LM, Clegg MS and Keen CL (1997) Comparative effects of essential and nonessential metals on preimplantation mouse embryo development in vitro. Toxicology 116 123-131

Harper AF, Lindemann MD and Kornegay ET (1996) Fetal survival and conceptus development after 42 days of gestation in gilts and sows in response to folic acid supplementation Canadian Journal of Animal Science 76 157-160

Hatfield PG, Daniels JT, Kott RW and Burgess DE (1999) Role of supplemental vitamin $\mathrm{E}$ in neonatal and lamb survival Journal of Animal Science 77 Supplement 1366

Hawk SN, Uriu-Hare JY, Daston GP, Jankowski MA, Kwik-Uribe C, Rucker RB and Keen CL (1998) Rat embryos cultured under copper-deficient conditions develop abnormally and are characterised by an impaired oxidant defense system Teratology 57 310-320

Hunt CD and Idso JP (1995) Moderate copper deficiency during gestation and lactation affects dentate gyrus and hippocampal maturation in immature male rats Journal of Nutrition 125 2700-2710

Jankowski MA, Uriu-Hare JY, Rucker RB, Rogers JM and Keen CL (1995) Maternal zinc deficiency, but not copper deficiency or diabetes, results in increased embryonic cell death in the rat: implications for mechanisms underlying normal development Teratology 31 85-93 
Jankowski-Hennig MA, Clkegg MS, Daston GP, Rogers JM and Keen C (2000) Zinc-deficient rat embryos have increased capase 3-like activity and apoptosis Biochemical and Biophysical Research Communications $271250-256$

Johnson MH and Nasr-Esfahani MH (1994) Radical solutions and cultural problems: could free oxygen radicals be responsible for the impaired development of mammalian embryos in vitro? Bioessays 16 31-38

Kane MT and Bavister BD (1988) Vitamin requirements for development of eight-cell hamster embryos to hatching blastocysts in vitro. Biology of Reproduction 39 1137-1143

Kastner P, Grondona JM, Mark M, Gansmuller A, LeMeur M, Decimo D, Vonesh J-L, Dolle P and Chambon P (1994) Genetic analysis of RXR $\alpha$ developmental function: convergence of RXR and RAR signalling pathways in heart and eye morphogenesis Cell 78 987-1003

Keen CL, Lonnerdal B, Golub MS, Uriu-Hare JY, Olin KL, Hendrickx AG and Gershwin ME (1989) Influence of marginal maternal zinc deficiency on pregnancy outcome and infant zinc status in rhesus monkeys Pediatric Research 26 470-477

Keen CL, Uriu-Hare JY, Hawk SN, Jankowski MA, Daston GP, Kwik-Uribe CL and Rucker RB (1998) Effect of copper deficiency on prenatal development and pregnancy outcome American Journal of Clinical Nutrition 67 1003S-1011S

Kwik-Uribe CL, Golubt MS and Keen CL (1999) Behavioural consequences of marginal iron deficiency during development in a murine model Neurotoxicology and Teratology 21 661-672

Lea R, Antipatis C, Gambling L, Charania Z, Roberston D, Hannah L, Ashworth CJ and McArdle HJ (2000) The effects of iron and vitamin A deficiency during pregnancy on placental cytokine expression Journal of Reproduction and Fertility Abstract Series $\mathbf{2 5} 14$

Lelievre-Pegorier M, Vilar J, Ferrier ML, Moreau E, Freund N, Gilbert T and Merlet-Benichou C (1998) Mild vitamin A deficiency leads to inborn nephron deficit in the rat Kidney International 54 1455-1462

Lindemann MD (1993) Supplemental folic acid: a requirement for optimizing swine reproduction Journal of Animal Science 71 239-246

McArdle HJ and Ashworth CJ (1999) Micronutrients in fetal growth and development British Medical Bulletin 55 499-501

McKiernan SH and Bavister BD (2000) Culture of one-cell hamster embryos with water soluble vitamins: pantothenate stimulates blastocyst production Human Reproduction 15 157-164

Maden M (2000) The role of retinoic acid in embryonic and post-embryonic development Proceedings of the Nutrition Society 59 65-73

Masters DG, Keen CL, Lonnerdal B and Hurley LS (1983) Zinc deficiency teratogenicity: the protective role of maternal tissue catabolism Journal of Nutrition 113 905-912

Matte JJ, Girad CL and Brisson GJ (1984) Folic acid and reproductive performance of sows Journal of Animal Science 59 1020-1025

Menino AR, Damron WS, Henry TE and O'Claray JL (1986) The influence of dietary copper on reproduction, growth and cardiovascular system in Swiss-Webster female mice Laboratory Animal Science 36 164-167

Mercer JF, Livingston J and Hall B (1993) Isolation of a partial candidate gene for Menkes disease by positional cloning Nature Genetics 3 20-25

Olson SE and Seidel GE (2000) Culture of in vitro produced bovine embryos with vitamin E improves development in vitro and after transfer to recipients Biology of Reproduction 62 248-252

Oteiza PI, Hurley LS, Lonnerdal B and Keen CL (1990) Effects of marginal zinc deficiency on microtubule polymerisation in the developing rat brain Biology of Trace Element Research 24 13-23

Oteiza PI, Clegg MS, Zago MP and Keen CL (2000) Zinc deficiency induces oxidative stress and AP-1 activation in 3T3 cells Free Radical Biology and Medicine 28 1091-1099

Paksy K, Foracs Z and Gati I (1999) In vitro comparative effect of $\mathrm{Cd}^{2+}, \mathrm{Ni}^{2+}$ and $\mathrm{Co}^{2+}$ on mouse blastocyst development Environmental Research 80 $340-347$
Peters JM, Wiley LM, Zidenburg-Cherr S and Keen CL (1991) Influence of short-term maternal zinc deficiency on the in vitro development of preimplantation mouse embryos Proceedings of the Society of Experimental Biology and Medicine 198 561-568

Peters JM, Wiley LM, Zidenburg-Cherr S and Keen CL (1993) Influence of periconceptual zinc deficiency on embryonic membrane function in mice Teratology, Carcinogen, Mutagen 13 15-21

Robinson JJ, McEvoy TG and Sinclair KD (2000) Windows of developmental opportunity and disadvantage throughout pregnancy. In Fetomaternal Control of Pregnancy pp 55-57 Havemeyer Foundation Monograph Number 2

Rogers JM, Taubeneck MW, Daston GP, Sulik KK, Zucker RM, Elstaein KH, Jankowski MA and Keen CL (1995) Zinc deficiency causes apoptosis but not cell cycle alterations in organogenesis-stage rat embryos: effect of varying duration of deficiency Teratology 52 149-159

Rosenquist TH, Ratashak SA and Selhub J (1996) Homocysteine induces congenital defects of the heart and neural tube: effect of folic acid Proceedings National Academy of Sciences USA 9315 227-15 232

Sapin V, Dolle P, Hindelang C, Kastner P and Chambon P (1997) Defects of the chorioallantoic placenta in mouse RXRalpha null fetuses Developmental Biology191 29-41

Sarricolea ML, Villa-Elizaga I and Lopez J (1993) Respiratory distress syndrome in copper deficiency: an experimental model developed in rats Biology of the Neonate 63 14-25

Scholl TO, Hediger ML, Schall JI, Khoo C and Fisher RL (1996) Dietary and serum folate: their influence on the outcome of pregnancy American Journal of Clinical Nutrition 63 520-525

Schultz CL, Ross TT, Salisbury MW and Melton L (1999) Effects of supplementing ewes with D- $\alpha$-tocopherol on lamb serum and ewe colostrum immunoglobulin concentration and preweaning lamb growth Journal of Animal Science $\mathbf{7 7}$ Supplement 1503

Singh US, Saxena DK, Singh C, Murthy RC and Chandra SV (1991) Leadinduced fetal nephrotoxicity in iron-deficient rats Reproductive Toxicology 5 211-217

Steele CE, Jeffreys EH and Diplock AT (1974) The effect of vitamin E and synthetic antioxidants on the growth in vitro of explanted rat embryos Journal of Reproduction and Fertility 38 115-123

Storeng G and Jonsen J (1980) Effect of nickel chloride and cadmium acetate on the development of preimplantation mouse embryos in vitro. Toxicology 17 183-187

Takami M, Preston SL, Toyloy VA and Behrman HR (1999) Antioxidants reversibly inhibit the spontaneous resumption of meiosis American Journal of Physiology 276 E684-E688

Trembley GF, Matte JJ, Lemieux L and Brisson GJ (1989) Survival rate and development of fetuses during the first 30 days of gestation after folic acid addition to a swine diet Journal of Animal Science $\mathbf{6 7}$ 1173-1178

Weiner G, Wilmut I and Field AC (1978) Maternal and lamb breed interactions in the concentration of copper in tissues and plasma of sheep. In Trace Element Metabolism in Man and Animals 3 pp 469-472 Ed. M Kirchgessner. Freising-Weihenstephan, Technischen Universitat Munchen, Germany

Whaley SL, Hedgpeth S and Britt JH (1997) Evidence that injection of vitamin A before mating may improve embryo survival in gilts fed normal or high-energy diets Journal of Animal Science 75 1071-1077

Whaley SL, Hedgpeth VS, Farin CE, Martus NS, Jayes FCL and Britt JH (2000) Influence of vitamin A injection before mating on oocyte development, follicular hormones and ovulation in gilts fed high-energy diets Journal of Animal Science 78 1598-1607

White JC, Highland M, Kaiser M and Clagett-Dame M (2000) Vitamin A deficiency results in the dose-dependent acquisition of anterior character and shortening of the caudal hindbrain of the rat embryo Developmental Biology 15 263-284 